\title{
EDUCAÇÃO, ÉTICA ANIMAL E AMBIENTAL: destituindo o paradigma antropocêntrico
}

\author{
EDUCATION, ANIMAL AND ENVIRONMENTAL ETHICS: dismissing the anthropocentric \\ paradigm
}

\author{
Fabio Alves Gomes Oliveira \\ Maria Clara Dias ${ }^{2}$
}

Resumo: Este artigo pretende defender a urgência de promovermos uma revisão ampla do viés antropocêntrico que tem marcado os conteúdos programáticos das diversas disciplinas oferecidas nas escolas brasileiras, nos mais diversos segmentos. Nesse sentido, aposta em uma reflexão acerca da fundamentação ética sobre como os animais nãohumanos vem sendo apresentados nos diversos espaços formais de ensino. Creditamos que a consolidação do debate ambiental entorno de temas como lixo, poluição, saúde e conservação de espécies reitera $\mathrm{o}$ antropocentrismo e contribui para a inviabilização de demandas próprias aos animais e ao meio ambiente. Trata-se, assim, de conduzir o debate a um novo paradigma, qual seja: a busca por uma forma de educação não-especista. Para isso, pretendemos, em primeiro lugar, apresentar conceitos básicos convergentes da ética animal e ambiental, de modo a podermos identificar a questão relativa ao valor relacional presente no debate ambiental. A partir de um olhar diferenciado sobre o lugar dos animais e do meio-ambiente, pretendemos defender uma proposta pedagógica que assuma o papel de questionar as diversas formas de injustiças cometidas contra animais e meio ambiente e, ao mesmo tempo, apresentar a noção de capacidade imaginativa, capaz de estimular os indivíduos a refletirem sobre a relação humano-meio ambiente e humano-animal de forma mais empática, através da mobilização de recursos visuais, tais como filmes e fotografias.

Palavras-chave: Educação. Especismo, Empatia.

\begin{abstract}
This article intends to defend the urgency of promoting a broad revision of the anthropocentric bias that has marked the programmatic contents of the different disciplines offered in Brazilian schools, in most diverse segments. In this sense, it bets on a reflection on the ethical basis on how non-human animals are being presented in formal educational spaces. We believe that the consolidation of the environmental debate surrounding issues such as garbage, pollution, health and conservation of species reiterates anthropocentrism and contributes to the unfeasibility of animals and environmental issues. It is, therefore, to lead the debate to a new paradigm, namely: the search for a form of non-specific education. For this, we intend, firstly, to present convergent basic concepts of animal and environmental ethics, so that we can identify the question regarding the relational value present in the environmental debate. From a different perspective on the place of animals and the environment, we intend to defend a pedagogical proposal that assumes the role of questioning the various forms of injustices committed against animals and the environment and, at the same time, presenting the notion of capacity imaginative, capable of stimulating individuals to reflect on the human-environment-human-animal relationship more empathically, through the mobilization of visual resources such as films and photographs.
\end{abstract}

Keywords: Education. Speciesism. Empathy.

\section{INTRODUÇÃO}

\footnotetext{
${ }^{1}$ Professor do Departamento de Ciências Humanas da Universidade Federal Fluminense. Membro Permanente do Programa de Pós Graduação em Bioética, Ética Aplicada e Saúde Coletiva. E-mai: <fabioagoliveira@gmail.com>. ORCID: <http://orcid.org/0000-0002-0275-6595>

${ }^{2}$ Professora Titular de Filosofia do Departamento de Filosofia da Universidade Federal do Rio de Janeiro. Membro Permanente do Programa de Pós Graduação em Filosofia e do Programa de Pós Graduação em Bioética, Ética Aplicada e Saúde Coletiva. E-mail: < mcdias1964@gmail.com>.
} 
As sociedades ocidentais são claramente marcadas por uma compreensão antropocêntrica do mundo e das nossas relações para com as demais formas de vida existentes. Seu modelo educacional espelha este mesmo paradigma. Para promover uma formação diferenciada, capaz de compreender o mundo de forma menos antropocêntrica precisamos, antes de tudo, promover uma reflexão sobre o modo como nos relacionamos com os demais integrantes do planeta e sobre o modo como passamos a incorporar determinados indivíduos como foco de nossa consideração moral. Nossa proposta é a de que ao defendermos uma concepção moral mais inclusiva, conseguiremos justificar uma revisão das bases curriculares em vigor, de forma a promover uma formação voltada para o florescimento de todas as espécies animais, assim como do próprio meio-ambiente. Em suma, trata-se de uma aposta na revisão tanto do conteúdo das disciplinas, como dos métodos empregados no aprendizado, à luz de uma concepção mais abrangente dos seres que integram nossa comunidade moral, dos valores e compromissos a serem contemplados no processo de formação dos estudantes.

\section{FRONTEIRAS DA COMUNIDADE MORAL}

Para iniciar nossa trajetória, propomos investigar com base em que critérios nós, seres humanos, agentes racionais, delimitamos o âmbito da moralidade e atribuímos status moral às demais entidades.

À primeira vista, identificamos como estratégia argumentativa o recurso à reciprocidade e/ou simetria. Ou seja, a comunidade moral seria constituída por seres igualmente capazes de estabelecer relações mútuas. Em situações como estas, ou seja, marcadas pela simetria entre as partes, o agente/sujeito e o objeto da moralidade podem ter seus papeis alternados sem que a relação seja comprometida. As partes seriam, assim, constituídas de seres racionais, capazes de manifestar de forma racional seus propósitos e interesses e defendê-los diante de uma audiência igualmente qualificada. Qualquer inclusão de outros seres só poderia ser defendida indiretamente, tendo em vista a instrumentalização dos mesmos para promoção dos interesses dos agentes, ou dependeria exclusivamente de uma atitude altruísta coletiva partilhada. Este modelo é adotado pelas diversas teorias de base contratual, entre elas, teorias do Direito.

Uma segunda alternativa seria a adoção do critério do "pertencimento" à coletividade. Neste caso, o agente racional reconheceria que seres com os quais mantém relações assimétricas, tal como a relação de dependência, também seriam objeto de consideração moral, estando, portanto, dentro dos limites da comunidade moral e garantindo a eles um status moral, ainda que, em muitos casos, hierarquicamente inferior. Esta segunda alternativa é, por exemplo, compatível com a perspectiva moral da ética do cuidado ${ }^{3}$ e o ecofeminismo ${ }^{4}$, onde os compromissos morais recaem sobre os vínculos estabelecidos entre os diversos indivíduos

Esta percepção do que seja ser um integrante da comunidade moral talvez explique a razão pela qual nos parece trivial reconhecer crianças, doentes mentais e outros seres humanos como objeto de consideração moral. Afinal, eles estão sob o nosso cuidado e proteção. Com eles, partilhamos grande parte de nossas vidas, compartilhamos experiências e traçamos parte de nossas aspirações para o futuro. Desta forma, costumamos incluir como objeto de nossa consideração moral até mesmo seres humanos que ainda não existem ou que talvez nem venham a existir. Pensamos no futuro dos nossos netos, quando nossos filhos são ainda crianças. Idealizamos um mundo melhor para gerações que não viremos a conhecer. Esta projeção, aparentemente pouco racional, dos nossos interesses, no interesse por outros seres humanos é simplesmente parte da nossa forma de estar no mundo e nenhum agente racional parece poder deixar de reconhecer a evidência de tais vivências.

Este mesmo reconhecimento pela via do pertencimento pode ser também estendido a animais não humanos. Deste modo, exigimos, de forma igualmente trivial, consideração moral pelos nossos animais de estimação. Eles são, em muitos casos, nossos maiores companheiros. Cães e seres humanos, por exemplo, já estabeleceram um vínculo que ninguém mais parece questionar. O surpreendente, nestes

\footnotetext{
3 Sobre a ética do cuidado, ver CAROL GILLIGAN. A Different Voice: Psychological Theory and Women's Development. Cambridge M.A: Harvard University Press, 1982

4 Sobre o ecofeminismo, ver CAROL J. ADAMS, LORI GRUEN (ed.) Ecofeminism: Feminist Intersections with Other Animals and the Earth. Bloomsbury Academic, 2014
} 
casos, é que muitas vezes não conseguimos estender nossa consideração moral para além do objeto específico do nosso vínculo. Na maior parte dos casos, nosso animal de estimação é parte de nossa família, o do vizinho é mais um cachorro ou um gato que nos perturba o sono. Não acreditamos dever a ele a mesma consideração, ainda que saibamos que eles pertencem à nossa coletividade. $O$ respeito aos animais de estimação de outros seres humanos é muitas vezes uma derivação do nosso respeito ao que seria reconhecido como objeto de estima de outro ser humano. É desta forma, por exemplo, que o Direito tradicional inclui a consideração aos animais não humanos enquanto propriedade de seres humanos. Estes casos, contudo, são apenas distorções e, para afastá-los, poderíamos facilmente recusar que o critério utilizado esteja sendo realmente o do pertencimento.

Se nossa análise estiver correta, temos, então, um problema. Ou bem o critério do pertencimento está sendo aqui erroneamente interpretado como relacionado ao vínculo que estabelecemos com certos indivíduos, ou não podemos adotá-lo como critério de reconhecimento de status moral, numa perspectiva que se quer universalista. Pois teríamos dificuldade de estender nossa consideração moral aos seres com os quais não estamos diretamente relacionados.

Uma terceira alternativa, que evidentemente não é incompatível com as demais, é a tentativa de identificar uma característica ou atributo comum a todos os seres que fazem parte da nossa comunidade moral ideal. A vantagem desta alternativa frente às anteriores é que ela pode ser aceita pelas demais, mas pode ser também mais abrangente, negando as características elencadas pelas alternativas anteriores e recorrendo a algo mais básico. Neste sentido, poderíamos recusar a racionalidade e o pertencimento como focos identificatórios e delimitadores do nosso universo de consideração moral e recorrer a algo ainda mais geral e que nos permitisse, portanto, melhor resgatar a pretensão de universalidade de nossos juízos morais. Ao eleger algo mais básico como foco, estaremos também rompendo com a hierarquia moral concedida aos supostos seres racionais. Restaria, contudo, identificar que atributo seria capaz de promover a extensão da moralidade aqui almejada.

\section{SOBRE A IDENTIFICAÇÃO DOS CONCERNIDOS}

Uma das mais promissoras caracterizações dos concernidos é aquela que recorre a nossa natureza enquanto seres racionais. Seres racionais são capazes de fornecer argumentos, verificar hipóteses, analisar argumentos alheios e deliberar com base em suas ponderações. Num sentido kantiano, eles são seres capazes de realizar, através deste processo, uma abstração de todas as formas de coesão sensíveis e se deixar determinar por um princípio formal da razão. Ao agirem desta forma, eles instauram uma nova ordem no mundo natural: uma ordem determinada pelo próprio agente, enquanto ser livre de determinação sensível. A esta capacidade chamaremos autonomia ou poder de autodeterminação. Seres capazes de se autodeterminar elegem seus próprios fins. Reconhecer a sua "natureza" ou sua "essência" significa reconhecê-los como seres autodeterminados, autores de suas próprias vidas ou, nas palavras de Kant, como fins em si mesmos. A partir de tais considerações, é então gerado, em Kant, aquele que até hoje se impõe como o princípio moral por excelência, a saber, o imperativo categórico em sua segunda formulação: a consideração ou o respeito de tais seres como fins em si mesmos. Com isso fica moralmente vedada a instrumentalização, a coação ou a imposição fortuita de obrigações e metas heterônomas aos seres capazes de se autodeterminar.

Não pretendemos aqui entrar no mérito de ser ou não razoável associarmos racionalidade de forma tão veemente à autonomia e, sobretudo, à autonomia compreendida como liberdade de toda e qualquer determinação sensível. Podemos adotar uma versão contemporânea deste princípio como a da não instrumentalização de seres capazes de deliberar sobre seus fins (Tugendhat) ou dos princípios que estabelecem uma situação de fala ideal, para indivíduos capazes de integrar um discurso de fundamentação racional (Habermas). Podemos ainda interpretar a racionalidade e a capacidade de julgar de forma autônoma como uma condição necessária ao estabelecimento de situações contratuais simétricas. Enfim, o que pretendemos ressaltar é que a escolha da racionalidade e/ou do poder de autodeterminação como base de determinação de condutas e princípio morais, por mais branda que seja a interpretação dada a esta capacidade, delimita o âmbito da moralidade aos seres capazes de manifestála. Embora isto soe bastante familiar aos nossos ouvidos, precisamos compreender uma tal interpretação 
da moralidade e, por conseguinte, dos limites da nossa comunidade moral, deixa de fora grande parte dos seres com os quais mantemos relações, sejam eles humanos ou não.

Em suma, se eliminarmos o poder retórico de tais formulações e levarmos a sério a perspectiva segundo a qual nosso objeto de consideração moral são os seres capazes de eleger seus próprios fins, autores de sua própria narrativa de vida, seres conscientes e capazes de eleger seu próprio projeto de vida, deveremos descartar a possibilidade de incorporarmos como objeto de consideração moral bebês, deficientes mentais, indivíduos senis, futuras gerações e, até que se prove o contrário, nossos animais de estimação e a grande maioria de animais não humanos, entre outros. Se a exclusão destes seres nos causa repulsa e indignação, então devemos levar nossos sentimentos a sério e buscar algo mais básico que nos aproxime e assemelhe a todos estes seres.

A alternativa mais frequente é aquela já apontada por Hume e pelos utilitaristas clássicos, a saber: a vulnerabilidade ao prazer e à dor. Formalizando a escolha da vulnerabilidade ao sofrimento e ao prazer como característica de todos aqueles que acreditamos dignos de consideração, o princípio moral por excelência, ou seja, o princípio universal com base no qual julgamos a moralidade, justiça ou correção de nossas condutas e normas, passa a ser igualmente aquele que prescreve a maximização do prazer e a minimização do sofrimento de todos os concernidos. O então denominado princípio utilitarista irá sofrer diversas transformações no decorrer de sua história até chegar à versão sugerida por Singer da maximização dos interesses preferenciais. Nesta perspectiva é reconhecido que todos os seres sencientes têm interesses preferenciais, entre os quais podemos reconhecer o de viver uma vida o mais livre possível de sofrimento e prazerosa. Nosso compromisso moral seria, assim, a promoção dos interesses preferenciais de todos os seres sencientes.

Bastaria que reconhecêssemos que viver uma vida minimamente prazerosa e livre de sofrimento excessivo e evitável é um interesse preferencial nosso, para que então atribuíssemos este mesmo interesse aos demais seres que, como nós, são vulneráveis ao prazer e à dor. Quais são efetivamente os animais capazes de vivenciar o prazer e a dor, é, contudo, uma informação, que apenas a investigação empírica pode nos indicar.

Singer defende que os interesses preferenciais dos seres sencientes estão todos em um mesmo nível hierárquico. Se existe uma hierarquia, ela deveria estar entre o que Singer chama de interesses preferenciais e os demais interesses que os indivíduos porventura apresentem. A realização de interesses preferenciais é moralmente mais importante do que a realização de interesses de outra ordem, independente de quais sejam os indivíduos em questão. Isso significa que o interesse de um ser humano em comer qualquer espécie de carne animal é hierarquicamente inferior, ou seja, moralmente menos importante, do que o interesse de qualquer animal de não ser dolorosamente sacrificado e viver uma vida repleta de restrições.

O problema surge, no entanto, quando colocamos a pergunta pela existência ou não de hierarquia no caso em que estejamos diante de interesses preferenciais de seres humanos e interesses preferenciais de animais não humanos. Aqui, se acompanharmos apenas o que foi dito até agora, ou seja, se estivermos nos baseando apenas na senciência como critério, não haveria qualquer razão para privilegiar uma das partes. Singer, contudo, não acompanha este raciocínio e introduz uma nova variante, uma nova forma de consciência, a consciência que alguns indivíduos possuem acerca de seus projetos, suas escolhas, sua finitude, enfim, uma forma de consciência bem próxima da do agente moral. No caso de empate, os interesses preferenciais destes seres deverão ser privilegiados. Mas como justificar tal hierarquia dentro do modelo proposto? Aqui gostaríamos de introduzir uma terceira alterativa, não para garantir a hierarquia proposta por Singer, mas para afastar de vez o olhar antropocêntrico que sustenta nossos privilégios morais.

A terceira alternativa é a de que elejamos como foco os funcionamentos básicos de cada sistema funcional ${ }^{5}$. De acordo com esta perspectiva, o que almejamos sob o ponto de vista moral é que cada um

5 A identificação dos concernidos como sistemas funcionais e do foco de nossa consideração moral como os funcionamentos básicos dos diversos sistemas funcionais é defendida pela perspectiva dos funcionamentos 
realize da melhor forma possível, ou seja, em sua plenitude, os seus próprios funcionamentos, seu próprio projeto. Projeto este que não precisa mais ser interpretado como uma escolha racional de seres com poder de autodeterminação, mas pode simplesmente ser compreendido como a realização de um sistema funcional em todo o seu vigor. Concebida esta maneira, esta terceira alternativa é capaz de incorporar as demandas próprias a seres racionais e autodeterminados; as demandas dos seres sencientes, por uma vida minimamente prazerosa e livre de sofrimento excessivo e evitável e, finalmente, demandas caladas de sistemas diversos que almejam por uma forma própria de florescimento.

Se adotarmos como foco os funcionamentos básicos dos diversos sistemas e, ao mesmo tempo, compreendermos, como funcionamentos básicos, aqueles que garantem a identidade própria de cada sistema, então estaremos moralmente comprometidos com demandas diversas, incomensuráveis entre si e, consequentemente, não hierarquizáveis. Aqui a única hierarquia identificável será entre funcionamentos básicos e não básicos, porém não entre sistemas. A suposta simplicidade ou complexidade de um sistema não desempenhará qualquer papel no valor moral a ele atribuído. No caso de conflito entre funcionamentos básicos de sistemas distintos, teremos que mensurar o peso dos funcionamentos em questão, no âmbito de cada sistema.

\section{UMA PERSPECTIVA MORAL MAIS ABRANGENTE}

Uma caracterização dos concernidos que destaque seus funcionamentos básicos tem como consequência uma desmistificação da ideia de ser humano/pessoa. ${ }^{6}$ Sob o ponto de vista moral, a consequência mais imediata é uma desantropologização da moralidade. Não interessa se certos indivíduos são ou não humanos. O que importa é que possamos identifica-los como sistemas funcionais específicos e que a realização dos funcionamentos que constituem sua identidade enquanto indivíduos particulares não estejam sendo colocada em risco por nós. Neste sentido, qual será, em cada caso, a decisão mais acertada, irá sempre depender do conjunto de funcionamentos em questão. Neste conjunto, poderão estar incluídos tanto funcionamentos bem básicos - tais como evitar o sofrimento e a vulnerabilidade física - como as capacidades mais complexas - tais como a capacidade de exercer a liberdade e integrar uma sociedade política e a capacidade de viver uma vida pessoal e profissional plena. Baseados unicamente em tais descrições, não teremos, portanto, razão para descriminar certas formas de vida e submeter algumas delas a um tratamento que desconsidera inteiramente seus funcionamentos mais básicos. Neste sentido, decisões acerca da utilização de animais para fins de lazer, alimentação, vestimentas, experimentos científicos ou estéticos humanos deverão tomar parte da agenda política de sociedades morais.

Seguindo este mesmo raciocínio, gostaríamos de ressaltar que, tal como as questões que envolvem animais não humanos, também questões ambientais vêm sendo discutidas moralmente sob um ponto de vista antropocêntrico. Ou seja, pensamos no meio-ambiente como um instrumento necessário para implementação da vida e dos interesses humanos. Neste sentido, "interesses" ambientais são interpretados, exclusivamente, como interesses de seres humanos por aspectos ambientais específicos. A dificuldade de pensar a questão ambiental de forma não instrumental está no fato de que evidentemente parece não fazer sentido atribuir funcionamento, tais como, fruição de prazer ou dor, ao Corcovado ou à nascente do Rio São Francisco. Neste ponto, nossa argumentação parecer chegar a um limite. Mas o que dizer então com relação ao meio-ambiente? Devemos excluí-lo de nossas considerações morais? Devemos incluí-lo como possuindo um valor instrumental?

elaborada por Dias. Sobre este tem ver: Dias, MC. Sobre Nós: expandindo as fronteiras da moralidade. Rio de Janeiro: Pirilampo, 2016 e Dias, MC (org.). A Perspectiva dos Funcionamentos: por uma abordagem moral mais inclusiva. Rio de Janeiro: Pirilampo, 2015.

${ }^{6}$ Pretendemos aqui recusar os preconceitos embutidos tanto na noção de ser humano quanto de pessoa, i.e. tanto o "especicistas" quanto o "personalismo". Acerca desta disputa entre especicistas e personalistas, ver: Singer, P. (1993): Practical Ethics, Cambridge: Cambridge University Press e Williams, B. (2006): "The Human Prejudice”, in B. Williams e A. W. Moore (eds.) Philosophy as a Humanistic Discipline, Princeton: Princeton University Press. 
Nossa proposta é a de que o Corcovado ou a nascente do São Francisco possuem para nós o mesmo valor não-instrumental que conferimos a outras entidades, tais como as obras de arte. Julgamos que destrui-las seja um erro ou uma falta moral, mesmo que jamais tenhamos desejado qualquer contato com algum delas. Posso jamais ter tido qualquer interesse pessoal em ir ao Corcovado, posso, ao contrário, ter medo de altura e desejar jamais ter que subir o Corcovado. Entretanto, isso não me impede de reconhecer que algo de valoroso se perderia de resolvêssemos destruí-lo.

Nosso diagnóstico da falácia relativa ao meio-ambiente está em pensar que um valor nãoinstrumental é necessariamente não-relacional. Se não houvesse vida humana sobre a terra, questões relacionadas à preservação do Rio São Francisco não seriam colocadas tal como aqui apresentamos e, por conseguinte, não seria atribuído um valor ao mesmo. Valores, do modo como aqui conceituamos, são atribuições humanas. Eles fazem parte do modo como nós nos reportamos às demais entidades. Isto, contudo, não significa que não possamos basear a nossa atribuição de valor em critérios objetivos, fazendo com que, a partir deste momento, o valor de algo possa independer dos nossos interesses e projeções pessoais.

O tipo de conduta que melhor expresse nosso respeito pelas demais formas de vida irá variar de acordo com os diversos contextos. E para sabermos a melhor forma de proceder, teremos que estar alertas aos "funcionamentos mais centrais", nem sempre explicitados dos que conosco convivem. Para garantirmos agora o respeito ou consideração à integralidade das formas de vida existentes, termos que deixar de lado regras morais pré-estabelecidas ou fórmulas gerais de conduta e conviver com a atitude de quem investiga, em cada caso, o que pode ser o melhor para cada forma de vida em questão. Tal procedimento envolve a necessidade de refletirmos sobre nossa própria situação, sobre situações alheias, sobre as consequências de nossas ações e as alternativas possíveis. Como então levar a cabo uma tal tarefa sem recorrermos a capacidade de criar protótipos, comparar e relacionar modelos de vida e de conduta e, sobretudo, sem assumirmos, ainda que sob a forma de um "experimento de pensamento", as perspectivas alheias? Se tais processos puderem ser reconhecidos como relacionados ao uso da nossa capacidade imaginativa, então poderíamos ainda perguntar: como podemos conceber uma forma de saber ou de racionalidade prática que já não seja ao mesmo tempo essencialmente imaginativa?

Defendemos aqui a tese de que apenas o exercício de nossa capacidade imaginativa nos permite decidir sobre a possível generalização de uma regra de conduta. Em outras palavras, considerando a tese central kantiana de que o predicado moral deve ser aplicado apenas às regras ou máximas do agir que puderem ser ao mesmo tempo consideradas como lei universal, ou seja, que satisfaçam o princípio de universalização, podemos agora dizer que a efetiva aplicação de um tal princípio supõe não um emprego formal da razão, mas seu uso imaginativo, apenas através do qual podemos percorrer as diversas posições a serem consideradas. Se quisermos, por exemplo, tomar uma posição em situações que envolvam os limites éticos das condutas científicas, tal como a aceitação ou não da manipulação de material genético, aprimoramento humano, eutanásia etc. teremos que ser capazes de abandonar o ponto de vista do legislador impessoal e adotar a perspectiva dos concernidos, em casos concretos. Em cada caso, estarão envolvidas diversas perspectivas que deverão ser consideradas a partir de sua lógica interna, ou seja, por referência ao universo de necessidades e convicções que lhe são próprias.

Por conseguinte, ao adotarmos uma perspectiva moral universalista, mais especificamente uma perspectiva moral segundo a qual nos dispomos a agir levando em consideração a perspectiva de todos os concernidos, nos comprometemos com um certo teatro imaginativo, onde nos propomos a ocupar qualquer dos papéis encenados. Ser moral, neste contexto, significa ser sensível à perspectiva alheia, compreender ou respeitar narrativas diversas ou, em termos humeanos, compadecer-se com os demais seres. O valor moral das mais diversas ações e normas adotadas será, assim, avaliado com base na sua contribuição para o aprimoramento ou realização plena das demais das formas de vida.

\section{A EDUCAÇÃO A PARTIR DE UM PARADIGMA NÃO-ESPECISTA}

De acordo com a perspectiva aqui defendida, podemos agora incluir no nosso universo de consideração moral não apenas seres humanos e animais não humanos, mas o próprio meio ambiente. Neste ponto, nossa principal dificuldade deixa de ser (i) encontrar uma justificativa para considerar o outro e passa a ser (ii) saber o que seria para cada sistema funcional em geral, ou para cada ser, em particular, sua realização plena. Trata-se, portanto, de um desafio para nossas investigaçõos empíricas e 
uma dificuldade técnica a ser suplantada pelo conhecimento humano acerca do mundo no qual está inserido.

Mas, se somos nós, humanos, que identificamos os sistemas e, de certa forma, reconhecemos suas necessidades e definimos sua forma de realização, não correríamos o risco de incorrer em uma antropomorfização dos demais seres? Independente de qualquer juízo de valor, somos nós, humanos, que construímos uma forma de vida moral. Somos nós, humanos, que tomamos outros seres como objeto de estudo, objeto de conhecimento e de consideração ou respeito moral. Tudo isso nos torna os agentes morais por excelência. A nós cabe a responsabilidade por uma vida moral e pelo tratamento que conferimos às demais entidades. Durante nosso processo de produção de conhecimento podemos ser induzidos ao erro de projetar nos demais seres características que marcam nossa própria espécie. Sob o ponto de vista moral, podemos ficar atentos a tal delito e desenvolver nossa capacidade imaginativa no sentido de ampliar nossa sensibilidade e capacidade empática para demandas antes imperceptíveis. Podemos dar menos ouvidos a nossa arrogância intelectual e mais voz aos nossos próprios sentimentos. Podemos ver e ouvir de forma menos "antropocêntrica" quem são e o que aspiram os "outros". Contra o delito na projeção no outro de nossas próprias demandas, estas são as únicas armas de que dispomos: um processo contínuo de sensibilização e escuta apurada do outro.

A moralidade, assim como o conhecimento humanos, estão obrigados a se render aos nossos próprios limites. Erraremos e transformaremos nossos erros em uma forma de aprendizado, mas não impediremos os impasses e conflitos morais que assolam nossa forma de estar no mundo junto a outros seres. Isso faz com que nossos juízos morais sejam essencialmente não-definitivos e que tenhamos que nos manter alertas a suas revisões, às transformações dos contextos e das demandas inerentes as diversas formas de existência.

Sob o ponto de vista pedagógico, resta-nos, portanto, o compromisso de conduzir nossos jovens a uma compreensão menos antropocêntrica da realidade e mais inclusiva da moralidade. Tal tarefa supõe não apenas uma revisão de todo o conteúdo programático das diversas disciplinas, afim de excluir seu componente especista, tal como já vem sendo feito com os componentes racistas e sexistas, como também a introdução de métodos de aprendizado diferenciados, capazes de promover empatia e uma sensibilização para o outro. Trata-se de promover uma formação voltada para a percepção das demandas alheias, para a sensibilização e desenvolvimento de uma certa razão imaginativa, compatível como exercício criativo de nos colocarmos no lugar do outro.

Neste sentido, o uso de outras linguagens torna-se fundamental para a ampliação da percepção e relação com os outros, sejam eles humanos, não-humanos ou o meio-ambiente. Entrar em contato com os conteúdos programáticos através de outras ferramentas, tal qual o recurso audiovisual, permite um entendimento mais abrangente de nossa relação com o mundo a nossa volta e de nós mesmos. Dessa abrangência acreditamos ser possível a aproximação da chamada educação artística com a educação filosófica, com o intuito de destacar o papel da empatia no processo de educação moral. Ou seja, evidencia o papel preponderante das artes no processo de formação de sujeitos sociais e políticos ativos em nossa sociedade.

O processo de sensibilização ética se expande para além dos limites dos muros das escolas; ela convoca uma aproximação entre discursos e experiências que comumente não ocupam lugar de destaque em nossas disciplinas e modos de compartilhar conhecimento que estão para além dos livros. Nesse sentido, cinema, teatro, dança, música, poesia, fotografia etc. devem ser ferramentas que ocupam o universo do aprendizado.

Entendendo a escola como o local por excelência da aquisição de linguagens formais (as linguagens biológicas, químicas, físicas, matemáticas, naturais etc.), e de socialização, o processo ordinário de aprendizagem que se dá basicamente a partir da leitura dos livros didáticos e pela assistência das explicações dos professores em sala de aula devem ser repensados. Os temas relacionados à ética e à política fazem parte do currículo de algumas disciplinas, mas temas considerados tabus ou menosprezados pelo paradigma antropocêntrico vigente, quando abordados o são de forma incipiente 
ou para reiterar o antropocentrismo. Neste sentido, novas linguagens são convocadas como forma de educação ética continuada.

Se estivermos corretos em afirmar que as expressões e manifestações artísticas comunicam algo sobre o mundo, guardando indícios da intencionalidade do artista e de uma retórica elíptica (DANTO, 2004), podemos questionar em que medida a arte também pode ser entendida como uma forma de não somente ocupar um lugar no mundo, mas de modificá-lo, recriá-lo e expandi-lo. Nesse processo de redesenhar o espaço, a empatia se torna elemento fundamental para dialogarmos com o outro, para entendermos vivências que extrapolam nosso universo de experiências pessoais. Ao fim, podemos concordar que "talvez seja a hora de fazermos com que os poetas e os músicos retornem à polis e nos ensinem a arte de saber viver segundo as leis do coração" (DIAS, 2016b).

\section{REFERÊNCIAS}

ADAMS, Carol, GRUEN, Lori. (ed.) Ecofeminism: Feminist Intersections with Other Animals and the Earth. Bloomsbury Academic, 2014

DIAS, Maria Clara. (org.) A Perspectiva dos funcionamentos: por uma abordagem moral mais inclusiva. Rio de Janeiro: Editora Pirilampo, 2015.

. Ensaios sobre a Moralidade. Rio de Janeiro: Editora Pirilampo, 2016

_. Sobre Nós: expandindo as fronteiras da moralidade. Rio de Janeiro: Editora Pirilampo, 2016b.

DIAS, Maria Clara; OLIVEIRA, Fabio Alves Gomes. (org.) Ética Animal: Um Novo Tempo. Rio de Janeiro: Editora Livros Ilimitados, 2018.

GILLIGAN, Carol. A Different Voice: Psychological Theory and Women's Development. Cambridge M.A: Harvard University Press, 1982:

HORTA, Oscar. El antropocentrismo y el argumento de los vínculos emocionales, em Dilemata, n. 1, 2009, pP 1-13.

PLUMWOOD, Val. Feminism and the Mastery of Nature. London-NY, Routledge, 1993.

PULEO, Alicia. Libertad, igualdad, sostenibilidad. Por un ecofeminismo ilustrado. Isegoría. Revista de Filosofía Moral y Política, 38, 2008: 39-59.

. Ecofeminismo para otro mundo posible. Madrid, Cátedra, 2011.

KANT, Immanuel. Grundlegung zur Metaphysik der Sitten. Werke, Frankfurt am Main: Suhrkamp, 1968.

REGAN, Tom. Animal Rights and Environmental Ethics. In: BERGANDI, Donato. The structural links between ecology, evolution, and ethics: the virtuous epistemic circle. Bioscience, Oxford University Press (OUP), 2014, 64 (3). pp.117-126.

REGAN, Tom. The Case for Animal Rights. In: SINGER, Peter (ed.). Defense of Animals. Blackwell, 1985.

SINGER, P. Libertação Animal. Trad. MarlyWinckler, ed Lugano, Porto Alegre, São Paulo, 2004.

_. Practical Ethics, Cambridge: Cambridge University Press e Williams, 1993.

WARREN, Karen. Ecofeminist Philosophy. A Western Perspective on What it is and Why it Matters. Oxford, Rowman and Littlefield, 2000.

MOORE, Adrian William (eds.) The Human Prejudice in Bernard Williams, Philosophy as a Humanistic Discipline, Princeton: Princeton University Press, 2006. 